\title{
Synthesis and properties of single-crystalline $\mathrm{Na}_{4} \mathrm{Si}_{24}$
}

Michael Guerette, ${ }^{1 *}$ Matthew D. Ward, ${ }^{1}$ Konstantin A. Lokshin, ${ }^{2,3}$ Anthony T. Wong, ${ }^{3}$ Haidong

Zhang, ${ }^{1}$ Stevce Stefanoski, ${ }^{1,4}$ Oleksandr Kurakevych, ${ }^{1,5}$ Yann Le Godec, ${ }^{5}$ Stephen J. Juhl, ${ }^{6}$ Nasim Alem, ${ }^{7}$ Yingwei Fei, ${ }^{1}$ Timothy A. Strobel ${ }^{*}$

${ }^{1}$ Geophysical Laboratory, Carnegie Institution of Washington, Washington, DC 20015, USA

${ }^{2}$ Shull Wollan Center - Joint-Institute for Neutron Sciences, Oak Ridge National Laboratory and University of Tennessee, Oak Ridge, TN 37831, USA

${ }^{3}$ Department of Material Science and Engineering, University of Tennessee, Knoxville, TN 37996, USA

${ }^{4}$ Department of Physics, Benedictine University, Lisle, Illinois 60532, USA

${ }^{5}$ IMPMC, UPMC Sorbonne Universités, UMR CNRS 7590, Muséum National d'Histoire Naturelle, IRD UMR 206, 75005 Paris, France

${ }^{6}$ Department of Chemistry, The Pennsylvania State University, University Park, PA 16802, USA

${ }^{7}$ Department of Materials Science and Engineering, The Pennsylvania State University, University Park, PA 16802, USA 


\section{ABSTRACT}

$\mathrm{Na}_{4} \mathrm{Si}_{24}$ is the precursor to $\mathrm{Si}_{24}$, a recently discovered allotrope of silicon. With a quasidirect band gap near $1.3 \mathrm{eV}, \mathrm{Si}_{24}$ has potential to transform silicon-based optoelectronics including solar energy conversion. However, the lack of large, pure crystals has prevented the characterization of intrinsic properties and has delayed deposition-based metastable growth efforts. Here, we report an optimized synthesis methodology for single-crystalline $\mathrm{Na}_{4} \mathrm{Si}_{24}$ with crystals approaching the millimeter-size scale with conditions near $9 \mathrm{GPa}$ and $1123 \mathrm{~K}$. Single-crystal diffraction was used to confirm the open-framework structure, and $\mathrm{Na}$ atoms remain highly mobile within the framework channels, as determined by electrical conductivity and electron energy loss spectroscopy (EELS) measurements. An epitaxial relationship between $\mathrm{Na}_{4} \mathrm{Si}_{24}$ and diamond cubic silicon (DC-Si), observed through high-resolution transmission electron microscopy (HRTEM), is proposed to facilitate the growth of high-quality $\mathrm{Na}_{4} \mathrm{Si}_{24}$ crystals from $\mathrm{DC}$-Si wafers mixed with metallic $\mathrm{Na}$, and could provide a viable path forward for scaling efforts of $\mathrm{Na}_{4} \mathrm{Si}_{24}$ and $\mathrm{Si}_{24}$.

\section{INTRODUCTION}

While silicon is a cornerstone of modern technology, the indirect nature of the fundamental band gap places limitations on desired applications. ${ }^{1-4}$ However, several other silicon allotropes are known, especially under high-pressure conditions. ${ }^{5,6}$ Among these, BC8 / R8, Si 136 clathrate and hexagonal diamond (HD)-Si can be stabilized at ambient conditions. ${ }^{5,7-13}$ In terms of optoelectronic properties, $\mathrm{Si}_{136}$ is particularly encouraging as it has a wide direct or nearly direct gap near $1.9 \mathrm{eV},{ }^{14-17}$ though some electronic dipole transitions are forbidden which detract from its potential photovoltaic merits. ${ }^{18}$ Additionally, challenges with large-scale / film growth and sample purity of $\mathrm{Si}_{136}$ have prevented major development thus far. ${ }^{12,14,19}$ Moreover, numerous 
allotropes with exceptional optical properties are predicted to exist with very small energy above the DC-Si ground state, ${ }^{4,5,20-22}$ suggesting potential for novel, metastable silicon allotropes with enhanced optoelectronic properties.

Recently, a new open-framework allotrope of silicon, $\mathrm{Si}_{24}$, was discovered using a high-pressure precursor synthesis method. ${ }^{23,24}$ In the first step of this process, a $\mathrm{Na}_{4} \mathrm{Si}_{24}$ precursor was synthesized at high pressure. $\mathrm{Na}_{4} \mathrm{Si}_{24}$ possesses the $\mathrm{Eu}_{4} \mathrm{Ga}_{8} \mathrm{Ge}_{16}(\mathrm{Cmcm})$ type structure ${ }^{25}$ with four formula units of $\mathrm{NaSi}_{6}$. This structure type is also known for some alkaline- and rare-earth silicides, $\mathrm{MSi}_{6}\left(\mathrm{M}=\mathrm{Ca}^{26}, \mathrm{Sr}^{27}, \mathrm{Ba}^{28}{ }^{28} \mathrm{Eu}^{29}, \mathrm{Na}^{23,24}\right)$. The structure consists of a clathrate-like $s p^{3}$ silicon host lattice comprised of five, six and eight-membered silicon rings that form channels along the crystallographic $a$-axis. The topology is isostructural with calcium aluminosilicate zeolite (code CAS), ${ }^{30}$ and the channels are filled with one-dimensional chains of metal guest atoms. This is unlike other known $\mathrm{Na}-\mathrm{Si}$ clathrates such as $\mathrm{Na}_{8} \mathrm{Si}_{46}$ (sI) and $\mathrm{Na}_{24} \mathrm{Si}_{136}$ (sII), where the host $\mathrm{Si}$ lattice forms complete polyhedral cages around the Na guest atoms, making Na difficult to remove from the structure. Na removal from from sI is not possible, while complete Na removal from sII is extremely difficult, requiring temperatures over $700 \mathrm{~K}^{14}$. $\mathrm{Na}_{4} \mathrm{Si}_{24}$ has loosely bonded $\mathrm{Na}$ ions in large channels that facilitate mobility, and, like the clathrate phases, $\mathrm{Na}_{4} \mathrm{Si}_{24}$ also exhibits potential for thermoelectric applications..$^{31,32}$

In the second step to produce $\mathrm{Si}_{24}, \mathrm{Na}_{4} \mathrm{Si}_{24}$ is recovered to ambient conditions and processed for Na removal. At $1 \mathrm{~atm}, \mathrm{Na}_{4} \mathrm{Si}_{24}$ is metastable with a formation enthalpy near $40 \mathrm{meV} / \mathrm{atom} .{ }^{24} \mathrm{~A}$ chemical potential driving force, combined with high Na mobility in the open channels sets favorable conditions for $\mathrm{Na}$ removal; ${ }^{23,33}$ heating at $400 \mathrm{~K}$ under dynamic vacuum $\left(10^{-5} \mathrm{mbar}\right)$ for eight days was shown as an effective technique for $\mathrm{Na}$ removal $(\mathrm{Na}<0.1$ at.\%) in multicrystalline samples with average grain sizes near $5 \mu \mathrm{m} .{ }^{23}$ The large ion mobility suggests potential 
applications in electrochemical energy storage, atomic-scale filtering applications, or as a skeleton template for creating other silicon compounds. When heated in air, previous observations show that $\mathrm{Si}_{24}$ decomposes near $750 \mathrm{~K} .{ }^{23}$

While $\mathrm{Na}_{4} \mathrm{Si}_{24}$ is metallic with the $\mathrm{Na} 3 s$ electrons filling the conduction band, $\mathrm{Si}_{24}$ is a semiconductor with band gap near $1.3 \mathrm{eV} .{ }^{23}$ While formally an indirect gap material, the dipoleallowed direct band gap is only $\sim 40 \mathrm{meV}$ higher energy than the indirect gap, and the material is therefore called "quasidirect." Unlike DC-Si which is strongly indirect $\left(E_{g, i}=1.1 \mathrm{eV}\right.$ vs. $E_{g, d}=3.4$ $\mathrm{eV}),{ }^{34,35}$ direct optical absorbance for $\mathrm{Si}_{24}$ could efficiently convert much of the solar spectrum to electrical energy as both an intrinsic or doped material. ${ }^{36} 1.3 \mathrm{eV}$ is nearly the ideal band gap for light conversion in the Shockley-Queisser limit for a single junction device. ${ }^{37,38}$

In this work we describe the optimal growth conditions of $\mathrm{Na}_{4} \mathrm{Si}_{24}$ in temperature, pressure and composition space, as ascertained by a multitude of experiments. Phase competition between other $\mathrm{Na}-\mathrm{Si}$ clathrates and kinetics of $\mathrm{Na}_{4} \mathrm{Si}_{24}$ growth are also considered. Previously, a suspected epitaxial relationship between $\mathrm{DC}-\mathrm{Si}$ and $\mathrm{Na}_{4} \mathrm{Si}_{2} 4$ was hypothesized to provide a synthesis pathway toward single crystals of $\mathrm{Na}_{4} \mathrm{Si}_{24}$ by altering precursor materials, which did lead to the growth of large single crystals ( size $>100 \mu \mathrm{m}$ ) of $\mathrm{Na}_{4} \mathrm{Si}_{24}{ }^{39}$ In this work we show evidence of epitaxy by direct observation of the interfacing phases with HRTEM. Having achieved this synthetic milestone, we explore some intrinsic properties of the phase, such as electronic properties and $\mathrm{Na}^{+}$ ion mobility.

\section{EXPERIMENTAL METHODS}

Experimental synthesis 
Synthesis was conducted between 8.0(5)-10.5(5) GPa and $773-1,273 \mathrm{~K}$ at the Geophysical Laboratory in a Walker-type multianvil press. ${ }^{40,41}$ Calibration and device details have been described by Bertka and Fei. ${ }^{42}$ 25.4-mm Toshiba F-grade tungsten carbide (WC) anvils with 8$\mathrm{mm}$ truncated edge length (TEL) were used to press the central $\mathrm{Cr}_{2} \mathrm{O}_{3}$-dopped $\mathrm{MgO}$ octahedron with 14-mm edge length per side (14/8 design). ${ }^{43}$ The anvils were separated and supported by pyrophyllite gaskets around the truncated corners. $\mathrm{A} \mathrm{ZrO}_{2}$ sleeve and graphite heater were centered within a cylindrical hole through the octahedron. $\mathrm{MgO}$ filler pieces packed the remaining space above and below the sample capsule within the central hole. Type $\mathrm{C}$ thermocouple wires (W5\%Re-W26\%Re ) of $254 \mu \mathrm{m}$ thickness were clad in 4-hole $\mathrm{Al}_{2} \mathrm{O}_{3}$ housing and inserted axially through an $\mathrm{MgO}$ sleeve to monitor temperature (See Supporting Information for schematics).

All experiments were performed via direct transformation of elemental silicon and sodium prepared under an inert argon environment $\left(<0.5 \mathrm{ppm} \mathrm{H}_{2} \mathrm{O}\right.$ and $\mathrm{O}_{2}$ ). Powdered DC-Si (Alfa Aesar 99.999\%) was ground with $\mathrm{Na}$ (Alfa-Aesar, $99.95 \%$ ), in a molar $\mathrm{Na}: \mathrm{Si}$ ratio ranging between 1:6.12 and 1:3.33 using an agate mortar. Special care was taken to ensure homogeneous mixing, which generally required 1 hour by hand. CAUTION: Na is reactive and should only be handled under an inert atmosphere. The homogeneous mixture was packed into a hexagonal boron nitride ( $h$-BN) capsule ( $\sim 15 \mathrm{mg}$ per run), sealed with a $h$-BN lid, then placed into the multianvil assembly. In some experiments, large pieces of single-crystalline DC-Si (intrinsic purity, float zone, $\rho>2 \times 10^{4} \Omega \cdot \mathrm{cm}$, University Wafer) was mixed with pieces of Na metal and packed into the $h$-BN capsule. ${ }^{39} \mathrm{~A}$ series of experiments with varying pressure, $P$, temperature, $T$, and composition were performed in order to optimize synthesis conditions to produce $\mathrm{Na}_{4} \mathrm{Si}_{24}$. After recovery to ambient conditions, samples were carefully removed from the multianvil assembly and $h$-BN capsule and washed with water / ethanol. 


\section{E-beam (SEM, FIB, TEM, SAED) characterization}

Initial e-beam characterization was conducted at the Geophysical Laboratory using a JEOL JSM6500F scanning electron microscope (SEM). Electron backscatter diffraction (EBSD) patterns were collected using the Oxford Nordlys Nano EBSD camera. The samples were tilted with surface normal being $70^{\circ}$ to the incident electron beam, with the detector angle at $90^{\circ}$. Energydispersive X-ray spectroscopy (EDXS) measurements were performed with an Oxford Instruments X-max detector $\left(80 \mathrm{~mm}^{2}\right)$. Samples were plasma-coated with $\operatorname{Ir}$ (approximately $10 \AA$ ) to facilitate electrical conductivity during EDXS and EBSD measurements. Aztec software ${ }^{44}$ was used for EBSD pattern recognition and EDXS data analysis.

The $\mathrm{Na}_{4} \mathrm{Si}_{24} / \mathrm{DC}-\mathrm{Si}$ interface was further investigated using high-resolution transmission electron microscopy (HRTEM) at Penn. State. Samples were prepared by focused ion beam (FIB) milling on an FEI Helios NanoLab 660 equipped with EDXS and EBSD. EDXS and EBSD mapping were employed to locate the interface between $\mathrm{Na}_{4} \mathrm{Si}_{24}$ and DC-Si. A sample perpendicular to the interface was rough-milled with the FIB and extracted, which measured approximately $2 \mu \mathrm{m} \times 12.5 \mu \mathrm{m} \times 10 \mu \mathrm{m}$. This sample was attached to a TEM grid and thinned for high-resolution TEM using an ultimate FIB beam energy of $2 \mathrm{kV}$. High-resolution imaging and STEM-EDXS were performed on a FEI Titan ${ }^{3}$ G2 S/TEM equipped with aberration correction and operated at $80 \mathrm{kV}$.

HAADF-STEM images were filtered with a band-pass Fourier-filter 3.34 1/nm - 14.826 1/nm.

$X R D$ 
Powder X-ray diffraction (XRD) patterns were collected on recovered multianvil samples and used as the primary tool to assess the phase composition. Data were collected using a Bruker D8 Discover diffractometer equipped with a $\mathrm{Cu} \mathrm{K}_{\alpha}(\lambda=1.5406 \AA)$ microfocus source and Vantec500 area detector. Phase identification and phase fraction refinements were performed using the Jade ${ }^{45}$ software.

Single-crystal X-ray diffraction data on $\mathrm{Na}_{4} \mathrm{Si}_{24}$ were collected at $100 \mathrm{~K}$ with the use of a Bruker APEX3 diffractometer equipped with graphite-monochromatized Mo $\mathrm{K}_{\alpha}(\lambda=0.71073 \AA)$ radiation. The crystal-to-detector distance was $60 \mathrm{~mm}$; the exposure time was $10 \mathrm{~s} /$ frame. Collection of intensity data and cell refinement were performed using the program APEX3 as a series of $0.5^{\circ}$ scans in $\theta$ and $\omega .{ }^{46}$ Data reduction was performed using APEX3. ${ }^{46}$ Face-indexed absorption, incident beam, and decay corrections were performed with the program SADABS. ${ }^{47}$ The structure was solved and refined with the use of the SHELX-14 suite of programs. ${ }^{48,49}$ Atom positions were standardized using the program STRUCTURE TIDY. ${ }^{50,51}$ Crystallographic images were made using the program CrystalMaker. ${ }^{52}$ Further details are given in Table 1.

In situ XRD was conducted during synthesis with a 1:6 Na:Si ratio of the elements at 8.0(5) GPa, as determined by the silicon equation of state $($ EoS $)$, heated at a rate of $0.2 \mathrm{~K} / \mathrm{s}$. Data were collected at beamline ID06 of the ESRF using a wavelength corresponding to $33 \mathrm{keV}$, which was selected from the emission of a U18 cryogenic undulator with a DC-Si (111) double-crystal monochromator. The beam was collimated to an area of $1 \mathrm{~mm}^{2}$. Pressures were generated and regulated using the 20MN Voggenreiter cubic press LPO 2000-1000/20 for triaxial loading.

Electrical properties 
For electronic property measurements, samples were potted in epoxies ${ }^{\circledR} 50-3122$ thermally conductive and electrically insulating epoxy. Electronic property measurements on $\mathrm{Na}_{4} \mathrm{Si}_{24}$ were made with two different geometries using a Quantum Design 9T Physical Properties Measurement System (PPMS) with a Keithley 2450 source/ measurement unit. Drive currents of $10 \mathrm{nA}$ were applied for sample resistances above $100 \Omega$, and $100 \mathrm{~mA}$ for sample resistances below $100 \Omega$.

In the first geometry, a $\mathrm{Na}_{4} \mathrm{Si}_{24}$ crystal of approximate size $100 \mu \mathrm{m} \times 100 \mu \mathrm{m} \times 20 \mu \mathrm{m}$ with unknown orientation was used. The flat and thin crystal with large parallel surfaces was placed in PPMS-type diamond anvil cell with $400 \mu \mathrm{m}$ anvils. Gold electrodes were sputtered on the diamond anvils and the crystal was lightly squeezed between the anvils with $\sim 2 \mu \mathrm{m}$ indium sheets contacting the crystal and the anvils on each side. Resistance was measured as a function of temperature from $300 \mathrm{~K}$ to $2 \mathrm{~K}$ at a rate of $1-3 \mathrm{~K} / \mathrm{min}$ in this two-probe orientation.

In the second geometry, a potted $\mathrm{Na}_{4} \mathrm{Si}_{24}$ single crystal of approximate size $180 \mu \mathrm{m} \times 160 \mu \mathrm{m} \times$ $30 \mu \mathrm{m}$ was polished and orientation determined by EBSD (see Supporting Information). The conductive Ir layer used during EBSD was removed before electrical measurement. Electrical leads ( $20 \mu \mathrm{m}$ gold wire) were bonded directly to the polished surface of the crystal. A "spot welding" technique was used to improve the contacts by applying a voltage in the range of 10$100 \mathrm{~V}$ across the two leads and limiting current to $0.01 \mathrm{~A}$ maximum. The pulse width for each "spot weld" was approximately $1.67 \mathrm{~ms}$. Current vs. voltage was measured in this geometry, with only two of the four surface probes used per measurement.

\section{RESULTS AND DISCUSSION}

Experimental synthesis 
Initial $\mathrm{Na}_{4} \mathrm{Si}_{24}$ synthesis efforts started with powdered DC-Si and metallic $\mathrm{Na}$ in a homogeneous mixture. The Na-Si phase diagram contains at least four compounds ( $\mathrm{Na}_{4} \mathrm{Si}_{4}$, sI: $\mathrm{Na}_{8} \mathrm{Si}_{46}$, sII: $\mathrm{Na}_{24} \mathrm{Si}_{136}$ and $\left.\mathrm{Na}_{4} \mathrm{Si}_{24}\right)$, three of which exist in a composition range spanning $\Delta \mathrm{Na}<1 \mathrm{~mol} \%$. sI and sII typically exist at lower pressures and can be differentiated by temperature, while $\mathrm{Na}_{4} \mathrm{Si}_{2}$ is observed above $\sim 8.0 \mathrm{GPa} .{ }^{24,53}$ Very small changes in composition can shift the phase equilibria and recent results indicate multiple $\mathrm{Na}$ occupancy within the clathrate cages of sII, further complicating the phase behavior. ${ }^{54}$ Therefore, the target phase of $\mathrm{Na}_{4} \mathrm{Si}_{24}$ exists within a fairly narrow $P, T, x$ region to be optimized experimentally. The results of experiments conducted between $8.0-10.5 \mathrm{GPa}$ and $773-1873 \mathrm{~K}$ with $0.14 \leq x_{\mathrm{Na}} \leq 0.23$ are summarized here with additional details provided in the Supporting Information .

With Na:Si ratios greater than 1:6 at pressures between 9.0-10.5 GPa, sII clathrate is the dominant phase in recovered multianvil experiments. sII clathrate likely melts congruently above the DC-Si melting temperature, although the pure compound may exhibit pressure-dependent nonstoichiometry. The small cages of sII clathrate can accommodate one $\mathrm{Na}$ atom and up to two $\mathrm{Na}$ atoms may reside within the large cages. ${ }^{54} \mathrm{Na}_{24} \mathrm{Si}_{136}$ through $\mathrm{Na}_{30.5} \mathrm{Si}_{136}$ have been observed, showing that in synthesis Na:Si ratio spans 1: $4.46-1: 5.67$. At $x_{\mathrm{Na}}=0.23$, it is relatively easy to grow single crystals of sII clathrate by cooling from the melt, e.g., from $1170 \mathrm{~K}$ at $9.0 \mathrm{GPa}$. Conversion to sII is always near $100 \%$ when enough $\mathrm{Na}$ is present to satisfy the compositional requirements of the structure type, and sII is also observed when the bulk Na composition is in excess of $\mathrm{Na}_{4} \mathrm{Si}_{24}$. In order to synthesize $\mathrm{Na}_{4} \mathrm{Si}_{24}$ and avoid sII, the bulk composition should be less than or equal to one sodium per six silicon atoms.

The optimum synthesis pressure of $\mathrm{Na}_{4} \mathrm{Si}_{24}$ was established by conducting variable pressure runs at fixed temperature and composition. Samples with a Na:Si ratio of 1:6 were compressed to 8.0, 
9.0, 10.0, and 10.5 GPa, and heated near $1073 \mathrm{~K}$. Previous studies indicate that a pressure near 8.0 GPa is required to form $\mathrm{Na}_{4} \mathrm{Si}_{24} .^{23,24}$ We confirm this result here, but also observed the formation of sI and sII clathrates in some runs, likely because of the extremely close compositions (e.g., $x_{\mathrm{Na}}$ $=0.143$ vs. 0.148 ). Higher pressures are therefore preferred to increase the phase fraction of $\mathrm{Na}_{4} \mathrm{Si}_{24}$, which is more energetically favorable than the clathrates at higher pressure. Because no significant difference in yield was found at 9.0, 10.0, and 10.5 GPa; 9.0 GPa was used in subsequent runs to help prolong the lifetime of the WC anvils.

At 9.0 GPa and a bulk Na:Si composition of 1:6, the phase fraction of $\mathrm{Na}_{4} \mathrm{Si}_{24}$ was found to be strongly dependent on synthesis temperature between $773-1173 \mathrm{~K}$. The recovered phase fraction of microcrystalline $\mathrm{Na}_{4} \mathrm{Si}_{24}$ increased with temperature to nearly $100 \%$ at $1123 \mathrm{~K}$, with DC-Si as the only other phase observed (Figure 1A), and the recovered phase fraction was relatively insensitive to dwell times between $0.5-16$ hours at the target temperature. When the temperature was increased to $1173 \mathrm{~K}$, only crystalline DC-Si was recovered with no observation of $\mathrm{Na}_{4} \mathrm{Si}_{24}$. These observations indicate a thermally activated kinetic process in which the elements are converted to $\mathrm{Na}_{4} \mathrm{Si}_{24}$ up to the melting temperature. We recall that the melting curve of DC-Si has negative pressure dependence, indicating system preference for the higher density of the melt compared to the solid. ${ }^{55-57}$ Unlike sII clathrate which forms readily from the melt, full melting is detrimental to $\mathrm{Na}_{4} \mathrm{Si}_{24}$ synthesis. This fact indicates that $\mathrm{Na}_{4} \mathrm{Si}_{2} 4$ melts incongruently and exhibits peritectic-type phase behavior. It is not optimal to synthesize single crystals from melt in the mutianvil apparatus when the liquid-solid coexisting region is limited in such a small field. Single crystal growth for incongruent systems is already challenging at ambient pressure. ${ }^{58-61}$

Given the challenges associated with crystal growth, several approaches were examined in order to produce larger grains including long conversion times and variable cooling rates. Runs with 
dwell times of several hours at the targeted temperature combined with a slow cooling rate (0.3$0.5 \mathrm{~K} / \mathrm{min}$ ) led to the first spotty Debye-Scherer rings in XRD patterns of the recovered sample with $300 \mu \mathrm{m}$ collimator, indicating some crystal content near this size scale (within a factor of 10 as a rough estimate). In an effort to mobilize the least stable atoms at grain boundaries without inducing thermal decomposition of $\mathrm{Na}_{4} \mathrm{Si}_{24}$, short thermal cycles $(\Delta \mathrm{T} \sim 200 \mathrm{~K}, t \sim 30 \mathrm{~s})$ near the melting point ( $\left.\mathrm{T} \sim 1,050 \mathrm{~K}, \mathrm{~T}_{\mathrm{m}} \sim 1,150 \mathrm{~K}\right)$ were used ${ }^{39}$ to encourage grain growth with significant improvement to overall grain size (Figure1B). This technique may be helpful for other synthesis attempts where phase stability is narrow and melting is incongruent.

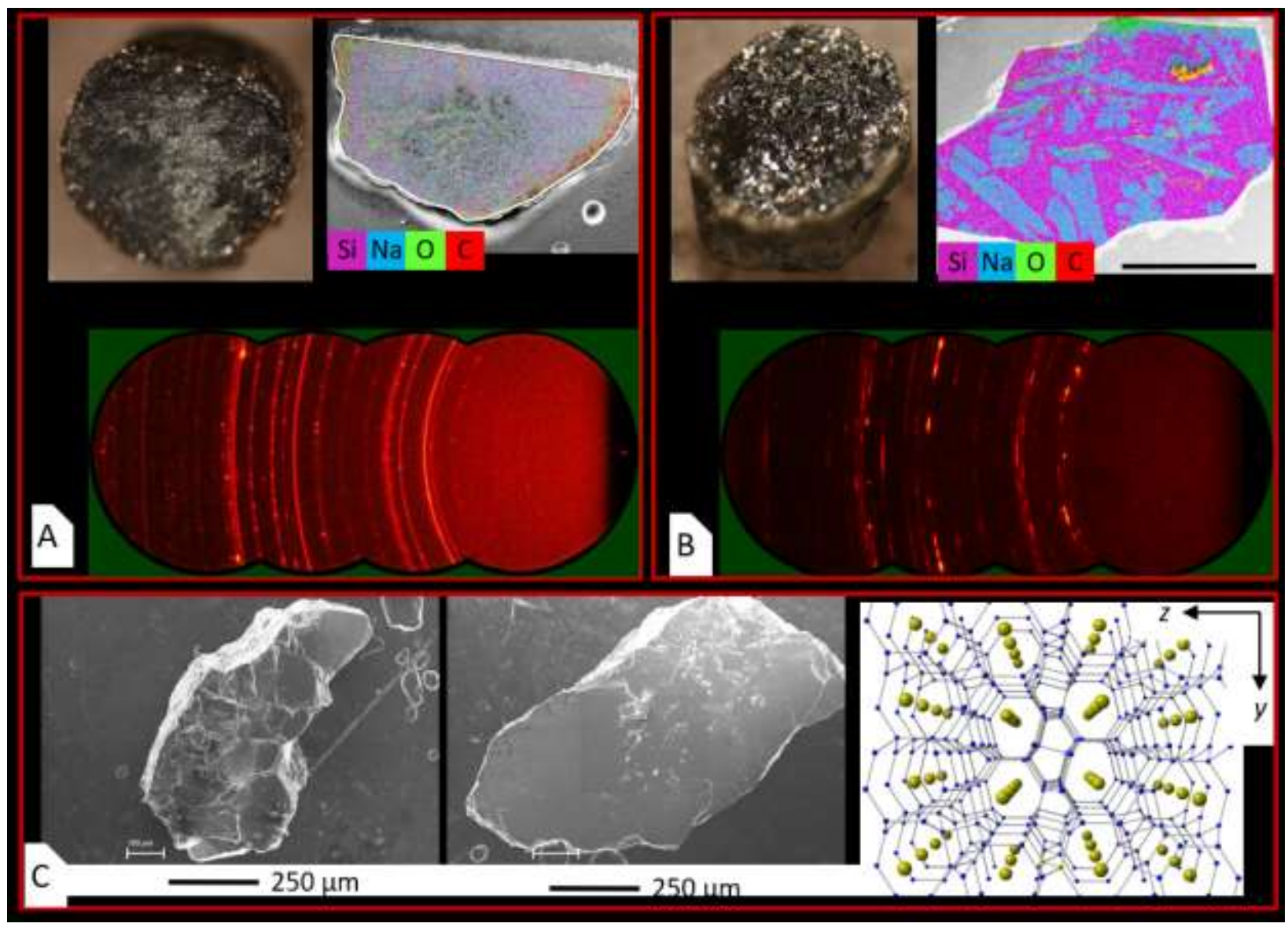

Figure 1. A) Typical multicrystalline synthesis result from powdered DC-Si + Na starting material at $9.0 \mathrm{GPa}$ and $1123 \mathrm{~K}$. Randomly oriented grains yield nearly uniform Debye-Scherer rings in 
the 2D-XRD image using a $300 \mu \mathrm{m}$ diameter incident beam. SEM and EDXS analysis indicate average grain sizes near 5-10 $\mu \mathrm{m}$ with a chemically homogeneous mixture of $\mathrm{Na}_{4} \mathrm{Si}_{24}$ and DC-Si impurity phase ( 15 wt\%). B) Large grains of $\mathrm{Na}_{4} \mathrm{Si}_{24}$ within a DC-Si matrix. Grain growth was achieved using the powdered DC-Si $+\mathrm{Na}$ starting material and by applying temperature cycles near the melting point at 9.0 GPa. The coarse grain structure gives incomplete powder averaging in the Debye-Scherer rings with a $300 \mu \mathrm{m}$ diameter incident beam, even while the sample undergoes $360^{\circ}$ rotation. C) Large single crystals of $\mathrm{Na}_{4} \mathrm{Si}_{24}$ achieved from single-crystalline DCSi starting material with pieces of $\mathrm{Na}$ at $9.0 \mathrm{GPa}$ and $1123 \mathrm{~K}$. Structure of $\mathrm{Na}_{4} \mathrm{Si}_{24}$ as refined through single-crystal XRD is viewed along the [100] direction.

When starting from powdered DC-Si, the largest grains obtained were achieved with a $\mathrm{Na}: \mathrm{Si}$ ratio of 1:6 at $9.0 \mathrm{GPa}$ with short thermal cycles breaching the melting point at $1123 \pm 20 \mathrm{~K}$. This procedure yields multicrystalline $\mathrm{Na}_{4} \mathrm{Si}_{24}$ samples with individual grains nearing $200 \mu \mathrm{m}$ and DCSi impurities between individual crystals (Figure 1B). To obtain larger single crystals of $\mathrm{Na}_{4} \mathrm{Si}_{24}$, a different synthesis technique was developed based on microanalysis observations. Microstructural and compositional analysis of the $\mathrm{Na}_{4} \mathrm{Si}_{24}$ interface with DC-Si has suggested possible coherency between the phases by lack of a faceted interface at the grain boundary. ${ }^{39}$ Interface coherency could allow for the synthesis of larger crystals of $\mathrm{Na}_{4} \mathrm{Si}_{24}$ through direct nucleation and growth on a favorable DC-Si surface. To test this method, large crystals of DC-Si were used with pieces of $\mathrm{Na}$, thus defining a new approach for the precursor material, as opposed to homogenous powders.

Experiments utilizing single crystalline DC-Si were performed at 9.0 GPa and $1123 \mathrm{~K}$ with Na:Si ratios ranging from 1:4 to 1:7. Recovered samples typically contained two or three phases 
depending on the bulk composition: DC-Si, sII and $\mathrm{Na}_{4} \mathrm{Si}_{24}$. sII was observed when the Na:Si ratio was far above 1:6 and typically multicrystalline, while DC-Si and $\mathrm{Na}_{4} \mathrm{Si}_{24}$ were most often found in agglomerates of large single crystals. Agglomerates of single crystals on the order of $1 \mathrm{~mm}$ were obtained by experiments covering the range of $1: 5.448$ to $1: 5.762 \mathrm{Na}$ :Si ratio. Other experiments with $\mathrm{Si}$ and $\mathrm{Na}$ ratios estimated by eye yielded single crystals of $\mathrm{Na}_{4} \mathrm{Si}_{24}$ also, though without recording initial composition (see Supporting Information for composition information where starting materials were measured). In the recovered agglomerates, freestanding crystals of $\mathrm{Na}_{4} \mathrm{Si}_{24}$ with dimensions greater than $100 \mu \mathrm{m}$ were obtained and potted for subsequent analysis; some crystals are greater than $500 \mu \mathrm{m}$ in maximum dimension (Figure 1C).

In situ $X$-ray Diffraction

In situ synthesis with a 1:6 Na:Si ratio of the element at 8.0 GPa was studied by XRD. The heating rate was $0.2 \mathrm{~K} / \mathrm{s}$ to capture the growth of $\mathrm{Na}_{4} \mathrm{Si}_{24}$ in detail, although this is roughly 8.5 times lower than the typical heating rate for the ex situ synthesis experiments reported in this work $(1.7 \mathrm{~K} / \mathrm{s}) .8 .0 \mathrm{GPa}$ is also a lower pressure than most of our experiments as reported here, with 9.0 GPa being the most targeted synthesis pressure.

Na melts readily ( 600(50) K, Figure $2 \mathrm{~A})$ to be dispersed throughout the system. One possible interpretation of the growth sequence is as follows. While DC-Si persists, the available system composition for reaction is rich in $\mathrm{Na}$ as compared to the ideal 1:6 Na:Si ratio for synthesis of $\mathrm{Na}_{4} \mathrm{Si}_{24}$. Since the sII clathrate cages can host multiple $\mathrm{Na}$ atoms $\left(\mathrm{Na}_{\mathrm{x}} \mathrm{Si}_{136}, 24 \leq \mathrm{x} \leq 30.5\right),{ }^{54}$ this phase is preferred until the excess DC-Si is converted (T 800-1100 K, Figure 2A). Once the Na:Si ratio of 1:6 has been obtained through decomposition of $\mathrm{DC}-\mathrm{Si}$, sII gives way to $\mathrm{Na}_{4} \mathrm{Si}_{24}$. (T 1100(100) K and above, Figure 2A). However, samples recovered from typical experiments with higher heating rate contain unreacted $\mathrm{Na}$ or $\mathrm{Na}_{4} \mathrm{Si}_{4}$ (samples visibly react with the moisture 
in air), and only DC-Si and $\mathrm{Na}_{4} \mathrm{Si}_{24}$ recovered phases. This observation suggests that sII may not be a required intermediate phase for $\mathrm{Na}_{4} \mathrm{Si}_{24}$ formation and that $\mathrm{Na}_{4} \mathrm{Si}_{24}$ may grow directly from DC-Si and Na.

In situ experiments reveal that $\mathrm{Na}_{4} \mathrm{Si}_{24}$, sII, and DC-Si coexist within a window of time and temperature (Figure 2B-C). Increased temperature (below $\mathrm{Na}_{4} \mathrm{Si}_{24}$ melt) and time favor $\mathrm{Na}_{4} \mathrm{Si}_{24}$ formation. With the slow heating rate used for this in situ study, the system spent an extended time in the sII stability field before entering that of $\mathrm{Na}_{4} \mathrm{Si}_{24}$. It is possible that the sII stability field is avoided by fast heating, leading to the absence of sII in recovered samples (see Supporting Information for recovered phase fraction as a function of heating time).

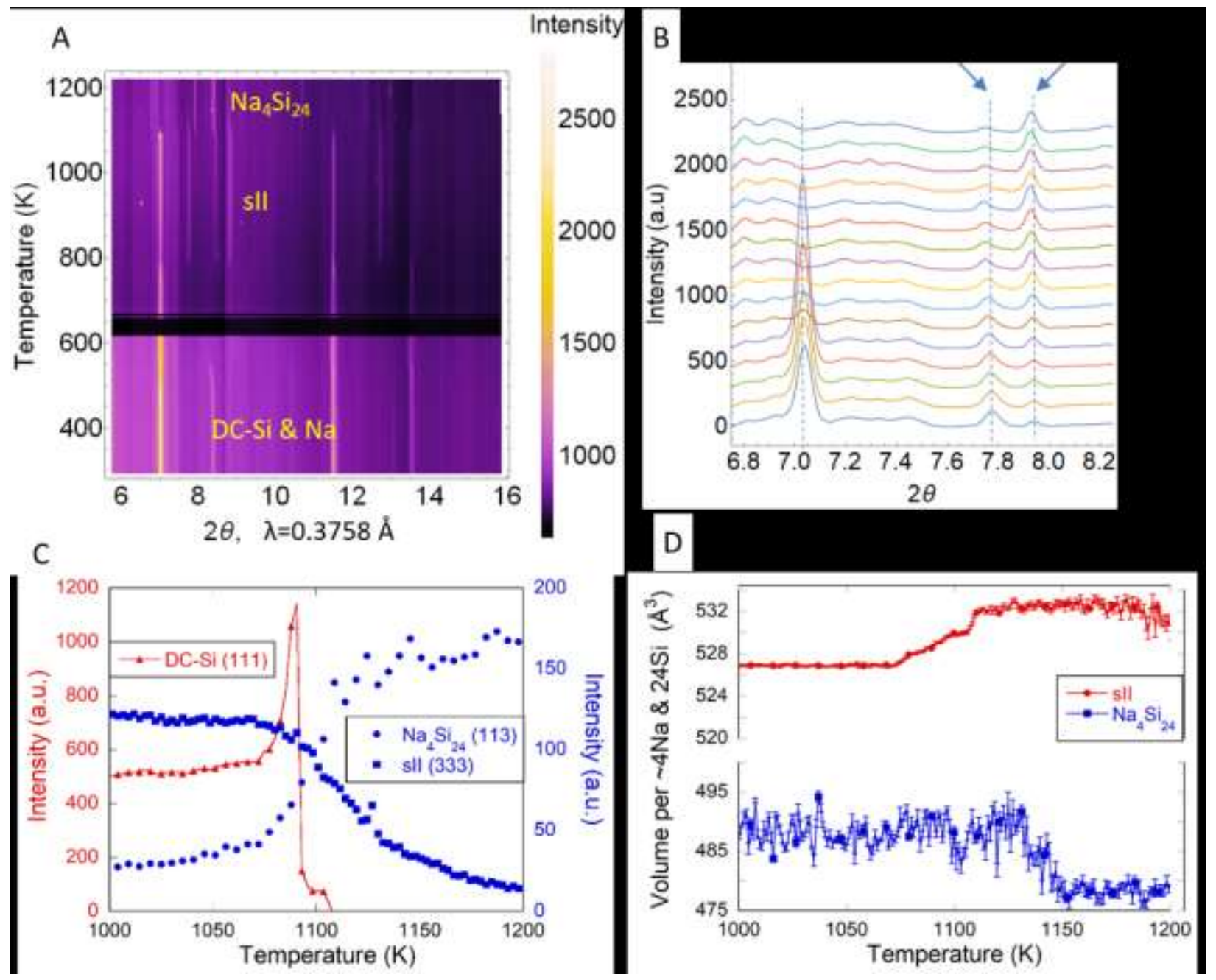


Figure 2. A) XRD file series (background subtracted) of in situ MA synthesis at 8.0 GPa. Reactants of elemental $\mathrm{Na} \& \mathrm{Si}$ mixed at 1:6 ratio were heated at a rate of $0.2 \mathrm{~K} / \mathrm{s}$. B) File series (every $7.8 \mathrm{~K}$ between 1070 and $1150 \mathrm{~K}$ ) which show the depletion of DC-Si and sII and the growth of $\mathrm{Na}_{4} \mathrm{Si}_{24}$. C) Intensity evolution of three competing phases. D) Volume for approximately $4 \mathrm{Na}$ $\& 24 \mathrm{Si}$ atoms in the present phases. For $\mathrm{Na}_{4} \mathrm{Si}_{24}$ this is the unit cell volume. For sII this is an estimate made by dividing the unit cell volume by 5.667 to give $\mathrm{Na}_{y} \mathrm{Si}_{24}(4.24<y<5.38)$.

Normalized cell volumes of $\mathrm{SII}$ and $\mathrm{Na}_{4} \mathrm{Si}_{24}$ have been plotted by increasing temperature and time (Figure 2D). This is a rough comparison between the $\mathrm{Na}_{4} \mathrm{Si}_{24}$ unit cell and a fractional volume of $\mathrm{Na}_{x} \mathrm{Si}_{136}(24<x<30.5)^{54}$ after dividing by 5.667 to give $\mathrm{Na}_{y} \mathrm{Si}_{24}(4.24<y<5.38)$. The sII normalized volume is always higher than that of $\mathrm{Na}_{4} \mathrm{Si}_{24}$. Throughout the experiment, high pressure should favor $\mathrm{Na}_{4} \mathrm{Si}_{24}$ if ignoring all other energy incentives. However, an energy incentive for conversion is observed to begin near $1075 \mathrm{~K}$ as sII normalized volume increases by $5 \AA^{3}$ to 532 $\AA^{3}$. Within this range, $\mathrm{Na}_{4} \mathrm{Si}_{24}$ unit volume remains nearly constant, stabilizing near $480 \AA^{3}$ at higher temperature (see Supporting Information for $\mathrm{Na}_{4} \mathrm{Si}_{24}$ lattice parameter information). One may consider the sII structure $\left(\mathrm{Na}_{\mathrm{x}} \mathrm{Si}_{136}, 24<\mathrm{x}<30.5\right)$ swelling to uptake excess $\mathrm{Na}$. The observed volume change $(\sim 1 \%)$ is roughly double the measured ex situ volume increase ${ }^{54}$ of $0.55 \%$ for the unit cell of $\mathrm{Na}_{30.5} \mathrm{Si}_{136}$.

This seems a natural result of having a system slightly rich in Na: the sII structure is stabilized by incorporating excess $\mathrm{Na}$ once $\mathrm{Si}$ is completely reacted. Recovered phase fraction of $\mathrm{Na}_{4} \mathrm{Si}_{24}$ accounted for $20 \%$ to $99 \%$, with the remainder as DC-Si in the majority of our ex situ experiments (see Supporting Information for recovered phase fraction as a function of temperature and heating time). Despite the unreacted $\mathrm{Na}$, sII did not form as an intermediary, and again we attribute this to avoiding the sII stability field by rapid heating. 
In situ observations demonstrate the importance of kinetics to $\mathrm{Na}_{4} \mathrm{Si}_{24}$ growth. The phase competition, which exists within narrow composition, pressure, and temperature coordinates, may favor the first phase to nucleate rather than the most stable phase in the system.

\section{Single Crystal X-ray Diffraction}

The synthesis of large, free-standing single crystals of $\mathrm{Na}_{4} \mathrm{Si}_{24}$ (Figure 1C) has enabled the first single-crystal structure refinement. Single-crystal X-ray diffraction (SXRD) results indicate high crystal quality and support previous refinements based upon powder diffraction measurements, ${ }^{23,24}$ and selected structural parameters are given in Table 1 . The crystal structure of $\mathrm{Na}_{4} \mathrm{Si}_{24}$ is provided in Figure 1C, showing the three-dimensional $s p^{3}$ silicon framework with channels along the $a$-axis occupied by Na. $\mathrm{Na}_{4} \mathrm{Si}_{24}$ crystallizes with four formula units in the orthorhombic space group $D^{17}{ }_{2 h}$ - Cmcm in the $\mathrm{Eu}_{4} \mathrm{Ga}_{8} \mathrm{Ge}_{16}$ structure type. ${ }^{25}$ The structure is composed of three crystallographically independent $\mathrm{Si}$ sites (all with site symmetry m..) and one $\mathrm{Na}$ site (site symmetry $m 2 m$ ). Each Si atom in the structure is four-coordinate with bonds to four other Si atoms in distorted tetrahedral environment (Figure 1C). Each Na atom is coordinated by fourteen nearest surrounding $\mathrm{Si}$ atoms of the framework. The $\mathrm{Si}-\mathrm{Si}$ distances in $\mathrm{Na}_{4} \mathrm{Si}_{24}$ range from 2.362(1) to 2.394(1) $\AA$ and may be compared to those seen in $\mathrm{BaSi}_{6}$ which range from 2.400 to $2.469 \AA$ at 293 $\mathrm{K} .{ }^{28}$ The Na-Si distances range from 3.187(1) to 3.145(1) A.. A complete list of bond distances is presented in the Supporting Information.

Table 1. Select crystallographic details for $\mathrm{Na}_{4} \mathrm{Si}_{24}$

\begin{tabular}{ll}
\hline Crystal System & Orthorhombic \\
Space Group & $C m c m$ \\
$a / \AA$ & $4.080(1)$ \\
\hline
\end{tabular}




\begin{tabular}{ll}
\hline$b / \AA$ & $10.572(1)$ \\
$c / \AA$ & $12.279(1)$ \\
$V / \AA^{3}$ & $529.63(4)$ \\
$Z\left(\mathrm{NaSi}_{6}\right)$ & 4 \\
Density, $\rho_{\text {calc }}\left(\mathrm{g} / \mathrm{cm}^{3}\right)$ & 2.402 \\
$\mathrm{~T} / \mathrm{K}$ & $100(2)$ \\
Absorption Coefficient $\left(\mathrm{mm}^{-1}\right)$ & 1.492 \\
Reflections Collected & 10,951 \\
Data/Parameters/Restraints & $470 / 23 / 0$ \\
Data Completeness & 1.000 \\
$R_{\text {int }}$ & 0.0366 \\
$R(F)[\mathrm{I}>2 \sigma(\mathrm{I})]^{\mathrm{a}}$ & 0.0231 \\
$R_{w}\left(F_{\mathrm{o}}^{2}\right)^{\mathrm{b}}$ & 0.0447 \\
$\left|\mathrm{II} / \sum\right| F_{\mathrm{o}} \mid$ for $F_{\mathrm{o}}^{2}>2 \sigma\left(F_{\mathrm{o}}{ }^{2}\right) .{ }^{b} R_{\mathrm{w}}\left(F_{\mathrm{o}}^{2}\right)=\left\{\sum\left[w\left(F_{\mathrm{o}}^{2}-F_{\mathrm{c}}{ }^{2}\right)^{2}\right] / \sum w F_{\mathrm{o}}^{4}\right\}^{1 / 2}$ for all \\
$\left.0.0118 F_{o}^{2}\right)^{2}$ for $F_{o}{ }^{2} \geq 0 ; w^{-1}=\sigma^{2}\left(F_{o}^{2}\right)$ for $F_{o}^{2}<0$.
\end{tabular}
data. $w^{-1}=\sigma^{2}\left(F_{o}^{2}\right)+\left(0.0118 F_{o}^{2}\right)^{2}$ for $F_{o}^{2} \geq 0 ; w^{-1}=\sigma^{2}\left(F_{o}^{2}\right)$ for $F_{o}^{2}<0$.

\section{Electronic Properties and Na Mobility}

We first attempted to measure the intrinsic electrical conductivity of single-crystalline $\mathrm{Na}_{4} \mathrm{Si}_{24}$ using the four-probe method. However, establishing Ohmic contacts proved challenging, as discussed below. Stable electrical transport measurements with a low contact resistance were achieved using a small diamond anvil cell for making contacts with light pressure. In this setup, an unpolished, as-recovered crystal of unknown orientation $(100 \mu \mathrm{m} \times 100 \mu \mathrm{m} \times 20 \mu \mathrm{m})$ was slightly pressed between the diamond anvils with a protective layer of indium on each side of the crystal. $R(T)$ measurements of $\mathrm{Na}_{4} \mathrm{Si}_{2}$, where $R$ is resistance, were obtained in this configuration between $300-3 \mathrm{~K}$ (Figure 3). In previous measurements, an anomalous resistance increase was observed below $75 \mathrm{~K}$ for a polycrystalline pellet. With the single-crystal measurements reported here, we are able to conclude that $\mathrm{Na}_{4} \mathrm{Si}_{24}$ exhibits normal metallic transport behavior, and we attribute the previous low-temperature anomaly to partial surface $\mathrm{Na}$ depletion, with the semiconducting behavior dominating at low temperature ( $\mathrm{Na}$ has been observed to leave the structure spontaneously even at ambient temperature). 
Observations of $\mathrm{Na}$ depletion and mobility were made when attempting four-probe conductivity measurements. A crystal oriented approximately along the [010] direction (see SI) was potted in epoxy and showed resistance above $2 \mathrm{k} \Omega$ after gold contact wires were bonded, indicating a significant loss of $\mathrm{Na}$ due to sample preparation or elapsed time since synthesis. In an attempt to improve the conductivity, the application of a current-limited voltage ("spot welding") in the range of $10-100 \mathrm{~V}$ across two selected wires allowed the resistance to gradually drop below $100 \Omega$. At the same time, the resistance between the other two wires increased up to $10 \mathrm{M} \Omega$. This behavior was found to be reproducible and independent of the contact pair between which the current was applied. Hence, in a four-probe wiring the resistance of a selected pair of contacts could be reproducibly varied by more than five orders of magnitude (Figure 3). This behavior is interpreted as current-induced sodium mobility where sodium migrates within the single crystal to participate in electronic conduction. It can be surmised that mobile $\mathrm{Na}^{+}$ions move to fill the channels in a partially depleted structure to lower electrical resistance.

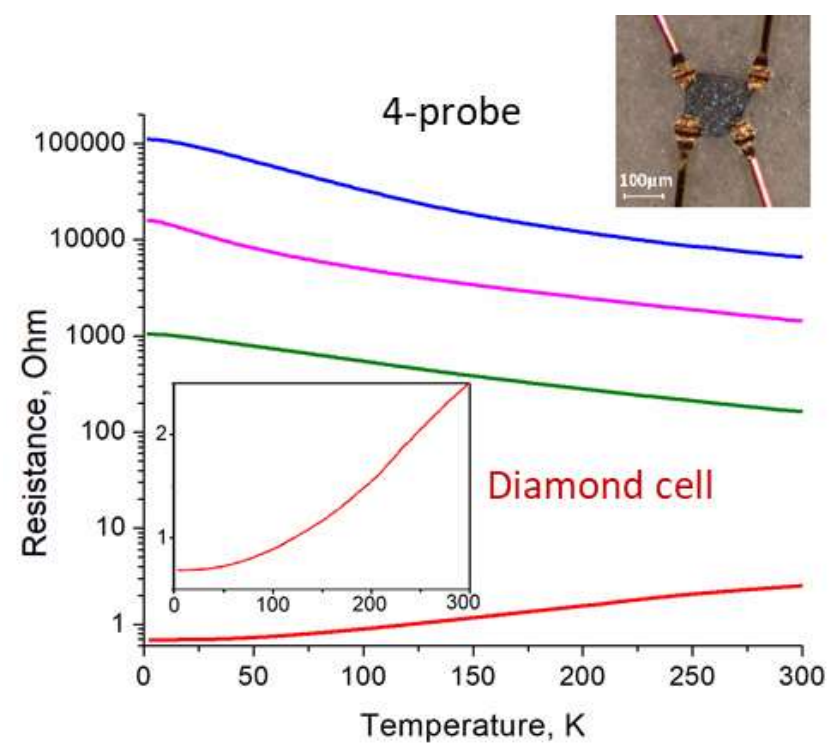

Figure 3. Electrical resistance as a function of temperature for $\mathrm{Na}_{4} \mathrm{Si}_{24}$ single crystals. The lowest resistance (red) curve shows the result from the two-probe diamond cell method and the inset 
shows normal metallic behavior at low temperature. The upper curves show the variation in resistance for the four-probe method with spot-welding. The resistance changes significantly between contacts indicating high Na mobility.

Our electronic measurements reflect high Na mobility within large single crystals of $\mathrm{Na}_{4} \mathrm{Si}_{24}$ on the measurement time scale. High Na mobility has been demonstrated previously by keeping a multicrystalline sample under dynamic vacuum for one week, leading to Na levels below 0.1 at $\%$ for $\sim 5-10 \mu \mathrm{m}$ crystallites. ${ }^{23}$ High Na mobility is also observed on the nanoscale from electron energy-loss spectroscopy (EELS) measurements. Figure 4A shows high resolution ADF-STEM images and two EELS measurements taken seven minutes apart. According to the EELS measurements, Na- $\mathrm{L}_{2,3}$ edge intensity at $31 \mathrm{eV}$ is dramatically reduced (Figure 4A). ADF-STEM images along $\mathrm{Na}_{4} \mathrm{Si}_{24}[100]$ (Figure 4B) show no observable sodium in the channels, though some sodium remains in place when a different $\mathrm{Na}_{4} \mathrm{Si}_{24}$ particle was viewed along $\mathrm{Na}_{4} \mathrm{Si}_{24}$ [001] (Figure 4C). The rapid reduction in the sodium EELS edge intensity and the absence of Na in HR-STEM images indicates that local heating or knock-on damage from the electron beam is sufficient to induce migration and confirms the rapid $\mathrm{Na}$ diffusion through the open channels. Our multicrystalline samples have also been noted to lose sodium even at ambient temperature when stored for several months. The high mobility of Na suggests that it should be removable from the structure on the bulk scale, which is encouraging for the synthesis of bulk $\mathrm{Si}_{24}$ crystals. 


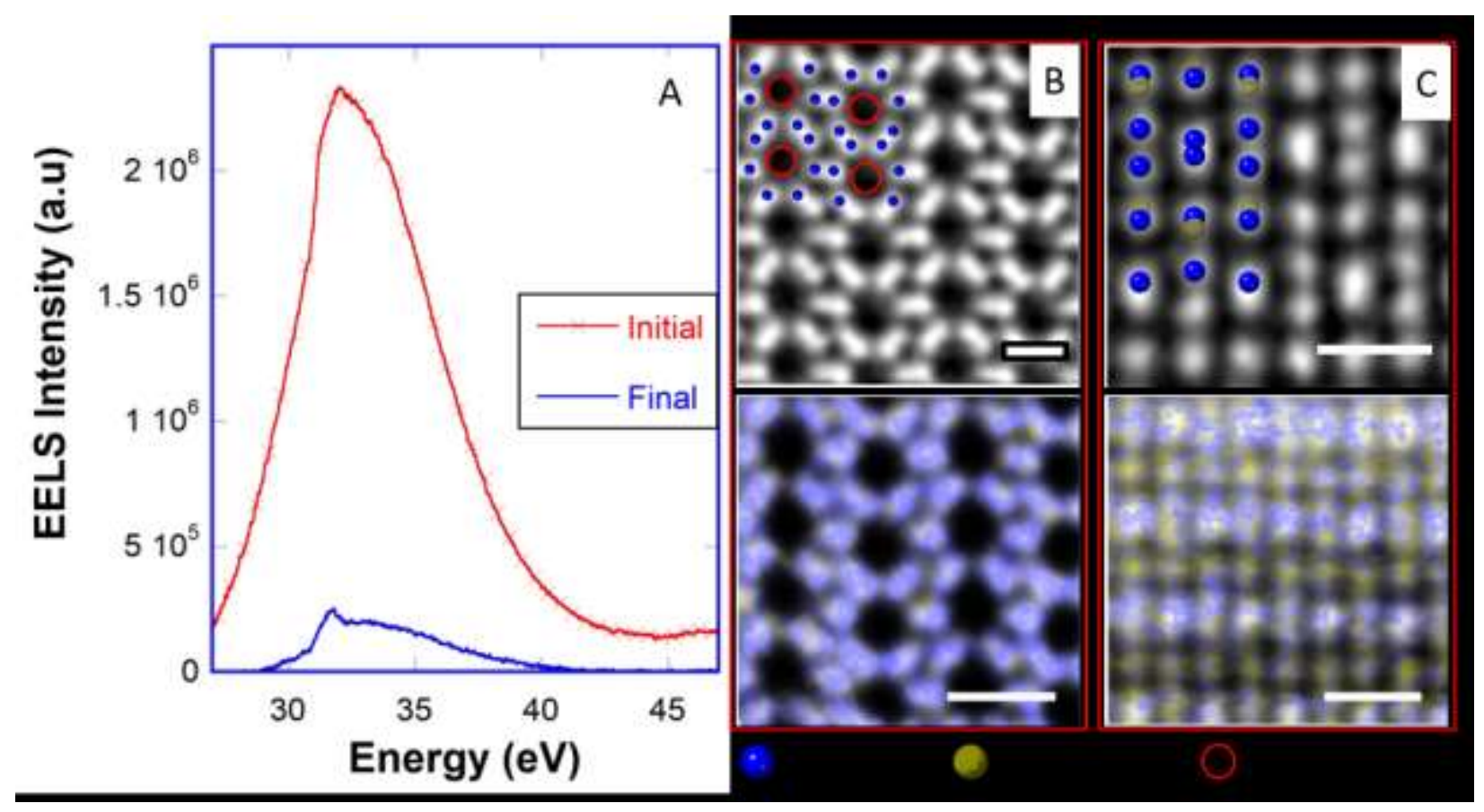

Figure 4. A) EELS shows dramatic desodiation under the electron beam $(80 \mathrm{kV}, 0.1 \mathrm{nA})$ after 7 minutes by observing the Na-L edge. B) HAADF-STEM and EDS-STEM imaging along $\mathrm{Na}_{4} \mathrm{Si}_{24}$ [100] reveal that high $\mathrm{Na}$ mobility in this direction render the $\mathrm{Na}$ invisible as it leaves the structure under the electron beam. C) HAADF-STEM and EDS-STEM imaging along Na4 $\mathrm{Si}_{24}$ [001] shows that $\mathrm{Na}$ remains in the structure, in contrast to imaging along $\mathrm{Na}_{4} \mathrm{Si}_{24}[100]$. Scale bars on the images are $0.5 \mathrm{~nm}$.

\section{Interface Coherency}

During microstructural analysis of recovered samples, the interface between $\mathrm{Na}_{4} \mathrm{Si}_{24}$ and DC-Si often exists without a faceted grain boundary (Figure 5A), suggesting the possibility of epitaxial coherency between these phases. ${ }^{43}$ In order to investigate this interface at the atomic scale, samples were prepared by FIB milling and examined using HRTEM (Figure 5B). 
Planes with different interplanar spacings $(d)$ may have equivalent atomic distances $(\gamma)$ at an interface with the appropriate angle of intersection $(\theta)$. The correct orientation of lattice planes between different phases can provide the conditions for coherency as in Figure 5C. Analysis of HRTEM images gives $\theta=27 \pm 1^{\circ}$, which is self-consistent with the measured interplanar spacings for the rows of lattice planes $\left(d_{\mathrm{Si}}=3.1 \pm 0.1 \AA, d_{N a_{4} S i_{24}}=2.8 \pm 0.1 \AA\right)$ approaching the interface in Figure 5B.

Of the interfacing rows of planes in Figure 5B, the larger measured interplanar spacing (3.1 $\AA$, upper right) is assigned unambiguously to $\mathrm{DC}-\mathrm{Si}\{111\}$ because there are no similar interplanar spacings in this crystal structure. To determine which $\mathrm{Na}_{4} \mathrm{Si}_{24}$ planes are responsible for the visual coherency of Figure 5B, $\theta$ was calculated for all potential $\mathrm{Na}_{4} \mathrm{Si}_{24}$ planes such that $\gamma_{N a_{4} S i_{24}}=d_{S i\{111\}}=d_{N a_{4} S i_{24}} / \cos (\theta)$. All planes within $0.25 \AA$ of the measured value were included in the search if they contain atoms (non-zero XRD intensity). Within $\theta=27 \pm 5^{\circ}$ there were only two contending planes within $\mathrm{Na}_{4} \mathrm{Si}_{24}$ that can accommodate the coherency condition with DC-Si $\{111\}$ (Table 2). 


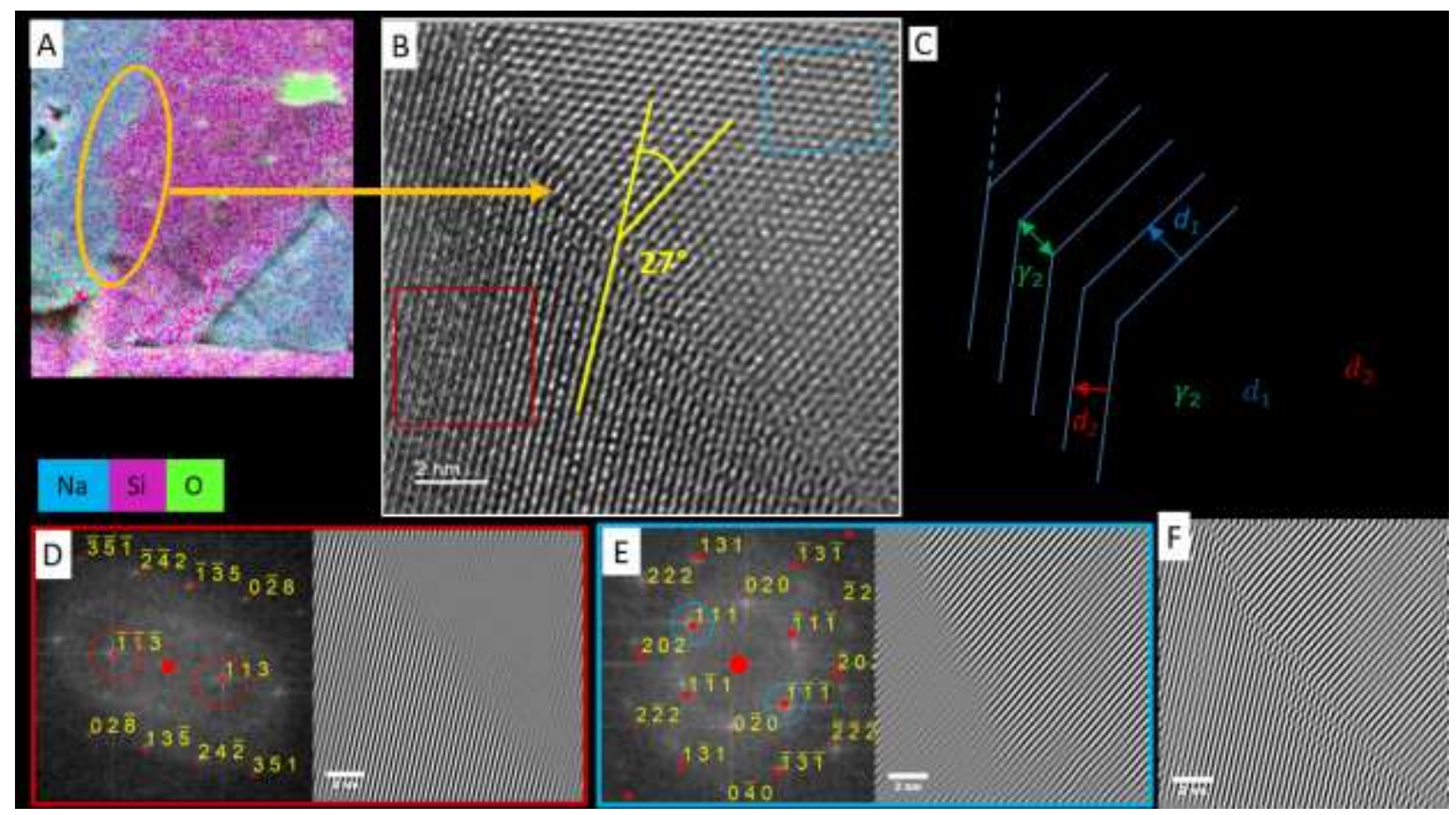

Figure 5. A) EDXS/SEM image of $\mathrm{Na}_{4} \mathrm{Si}_{24} / \mathrm{DC}-\mathrm{Si}$ interface often shows no facet and suggests a level of interface coherency. B) HRTEM image of $\mathrm{Na}_{4} \mathrm{Si}_{24} /$ DC-Si interface, showing angle of intersection of $27^{\circ}$ for coherency between planes of $d=3.1(1) \AA$ and $d=2.8(1) \AA$ for upper and lower regions, respectively. C) Schematic showing coherency obtained through rotation of planes with different interplanar spacing. D-E) The FFT of each area (colored frame corresponds to regions in part $\mathrm{B}$ ) is indexed to reveal that $\mathrm{DC}-\mathrm{Si}\{111\}$ and $\mathrm{Na}_{4} \mathrm{Si}_{24}\{113\}$ planes participate at this interface. Inverse fast Fourier transform (IFFT) reconstruction highlights the planes responsible for the encircled FFT contribution. F) Full IFFT reconstruction from the selected FFT contributions in parts D-E.

$\mathrm{Na}_{4} \mathrm{Si}_{24}\{113\}$ and DC-Si $\{111\}$ planes match the measured $d$-spacings from Figure 5B, and atomic spacing $(\gamma)$ is brought into equivalence for these planes at $\theta=27.26^{\circ}$ (Table 2). Fast Fourier Transform (FFT) pattern indexing is shown in Figure 5D-E. The indexed FFT for DC-Si shows that the forbidden reflections from $\{020\}$ planes appear as is common when viewed along 
$<011>$ directions because of secondary scattering from $\{111\}$ planes. $^{62}$ Inverse FFT (IFFT) $^{2}$ image reconstruction with $\mathrm{Na}_{4} \mathrm{Si}_{24}\{113\}$ and $\mathrm{DC}-\mathrm{Si}\{111\}$ reflections support these being the interfacing planes (Figure 5D-F). However, the imperfect coherency results in strained lattices, visible as symmetry distortions in the FFT (Figure 5D-E).

Table 2. Contending planes for coherency as observed in Figure 5B. Planes have $d$-spacing within $0.25 \AA$ of the measured interplanar spacings of DC-Si and $\mathrm{Na}_{4} \mathrm{Si}_{24}$ (3.1(1) and 2.8(1) $\AA$, respectively). The coherency angle $(\theta)$ is that required for atomic matching at the interface, and thus perfect coherency. $\Delta \theta$ is the difference between the calculated coherency angle and the measured interfacing angle of $27(1)^{\circ}$ in Figure $5 \mathrm{~B}$.

\begin{tabular}{|c|c|c|c|c|c|}
\hline $\begin{array}{c}\text { DC-Si } \\
\text { planes }\end{array}$ & $\begin{array}{c}\text { DC-Si } \\
\text { interplanar } \\
d \text {-spacing }(\AA)\end{array}$ & $\begin{array}{c}\mathrm{Na}_{4} \mathrm{Si}_{24} \\
\text { planes }\end{array}$ & $\begin{array}{c}\mathrm{Na}_{4} \mathrm{Si}_{24} \\
\text { interplanar } \\
d \text {-spacing }(\AA)\end{array}$ & $\begin{array}{c}\text { Coherency Angle } \\
(\theta)\end{array}$ & $\Delta \theta$ \\
\hline$\{111\}$ & 3.136 & $\{113\}$ & 2.787 & 27.26 & 0.26 \\
\hline$\{111\}$ & 3.136 & $\{130\}$ & 2.667 & 31.73 & 4.73 \\
\hline
\end{tabular}

The observations of a coherent interface between $\mathrm{Na}_{4} \mathrm{Si}_{24}$ and DC-Si can explain how large single crystals of $\mathrm{Na}_{4} \mathrm{Si}_{24}$ were achieved by starting with large single crystals of DC-Si. Furthermore, the coherency between this set of planes is suggestive of epitaxial growth opportunities. If successful, epitaxial growth of $\mathrm{Na}_{4} \mathrm{Si}_{24}$ could lead to scalable quantities of both this phase and $\mathrm{Si}_{24}$.

The ultimate utility of $\mathrm{Na}_{4} \mathrm{Si}_{24}$ and $\mathrm{Si}_{24}$ will be realized if thin film growth can be achieved. Several metastable materials can be grown on appropriate substrates to seed and support uniform growth. Synthetic diamond is a burgeoning industry and indicates the synthesis opportunities available within reach of modified chemical vapor deposition (CVD) techniques, including plasma 
enhanced (PE) dissociation of precursors. ${ }^{63-65}$ Recently, a tetragonal form of Si with interstitial hydrogen has been shown capable of epitaxial growth on heavily Boron-doped DC-Si (100) substrate at modest temperature and pressure $(T<623 \mathrm{~K}, P<400 \mathrm{~Pa})$ by PECVD. ${ }^{66}$ Shells of hexagonal diamond silicon (HD-Si) have been grown epitaxially on hexagonal GaP nanowires at $1173 \mathrm{~K} .{ }^{10}$ These examples show promise for growing supported films of other metastable forms of $\mathrm{Si}$, and even templating the silicon lattice with atoms of various size and chemical effects.

\section{CONCLUSION}

Many experiments have been conducted with powdered DC-Si mixed with Na to establish that $\mathrm{Na}$ :Si ratio of 1:6, pressure of $9.0 \mathrm{GPa}$ and temperature near $\sim 1123 \mathrm{~K}$, and rapid heating rate (1.7 $\mathrm{K} / \mathrm{s}$ ) were found to be optimum synthesis conditions for the $\mathrm{Na}_{4} \mathrm{Si}_{24}$ phase.

An alternate synthesis approach has been used for growth of large single crystals of $\mathrm{Na}_{4} \mathrm{Si}_{24}$ : large pieces of $\mathrm{DC}-\mathrm{Si}$ and pieces of elemental $\mathrm{Na}$ are used as the starting materials. This novel synthesis approach can yield grain sizes of $500 \mu \mathrm{m}$ and more, ${ }^{43}$ with agglomerates of phase-pure single crystals of $\mathrm{Na}_{4} \mathrm{Si}_{24}$ on the order of $1 \mathrm{~mm}$. This work shows that single crystals at $100 \mu \mathrm{m}$ can be isolated and measured.

Rapid Na mobility has been observed on the nm scale (Figure 4A-B). Na mobility has been previously demonstrated on the $\sim 5 \mu \mathrm{m}$ scale by effectively leaving the structure under dynamic vacuum for 1 week. ${ }^{23}$ Our electronic measurements show that Na remains mobile on bulk size scales. These observations suggest that Na should be removable from the structure on the bulk scale, which is again encouraging for the prospect of using $\mathrm{Si}_{24}$ in bulk for photovoltaic applications, among others. 
Interface coherency observed between $\mathrm{Na}_{4} \mathrm{Si}_{24}\{113\}$ and $\mathrm{DC}-\mathrm{Si}\{111\}$ planes suggests that $\mathrm{Na}_{4} \mathrm{Si}_{24}$ may be grown epitaxial to DC-Si. Understanding that coherency exists between planes of DC-Si and $\mathrm{Na}_{4} \mathrm{Si}_{24}$ will help to provide critical substrate preparation for thin film growth pursuits of this material. If successful, such efforts would be the key to industrial scale synthesis, justifying future efforts in this direction.

\section{AUTHOR INFORMATION}

\section{Corresponding Author}

*Email for correspondence: mguerette@ciw.edu and tstrobel@ciw.edu

\section{Author Contributions}

The manuscript was written through contributions of all authors. All authors have given approval to the final version of the manuscript.

\section{Notes}

The authors declare no competing financial interest.

\section{ACKNOWLEDGMENTS}

The authors express their gratitude to Dr. Jeffrey Bertke for his help and use of the X-ray Diffraction Facility at the Department of Chemistry, Georgetown University and to Olivia ReyesBecerra for assistance with multianvil synthesis experiments. The $\mathrm{Na}_{4} \mathrm{Si}_{24}$ synthesis experiments with in situ XRD were performed at the ID06 beamline (beamtime CH4109) at the European Synchrotron Radiation Facility (ESRF), Grenoble, France. We are grateful to W. Crichton and J. Guignard for providing assistance in using this beamline. This work was supported by the Energy Frontier Research in Extreme Environments Center (EFree) under award number DE-SC0001057. 


\section{ASSOCIATED CONTENT}

Supporting Information. Crystallographic data (cif file) for $\mathrm{Na}_{4} \mathrm{Si}_{24}$, synthesis details, interface analysis. This material is available free of charge via the Internet at http://pubs.acs.org.

\section{ABBREVIATIONS}

DC-Si, diamond cubic silicon;

EBSD, electron backscatter diffraction

EDXS, energy dispersive X-ray spectroscopy

FFT, fast Fourier transform

HAADF, high angle annular dark field

IFFT, inverse fast Fourier transform

PXRD, powder X-ray diffraction

SAED, selected area electron diffraction

SEM, scanning electron microscopy

STEM, scanning transmission electron microscopy

SXRD, single crystal X-ray diffraction

TEM, transmission electron microscopy

XRD, X-ray diffraction

( hkl) crystal plane

$\{h k l\}$ crystal plane family

$[u v w]$ crystal direction

$<u v w>$ crystal direction family

\section{REFERENCES}

(1) Ng, W. L.; Lourenco, M. A.; Gwilliam, R. M.; Ledain, S.; Shao, G.; Homewood, K. P. An Efficient Room-Temperature Silicon-Based Light-Emitting Diode. Nature 2001, 410 (6825), 192.

(2) Theis, T. N.; Solomon, P. M. It's Time to Reinvent the Transistor! Science 2010, 327 (5973), 1600-1601.

(3) Fujita, M. Silicon Photonics: Nanocavity Brightens Silicon. Nat. Photonics 2013, 7 (4). 
(4) Botti, S.; Flores-Livas, J. A.; Amsler, M.; Goedecker, S.; Marques, M. A. Low-Energy Silicon Allotropes with Strong Absorption in the Visible for Photovoltaic Applications. Phys. Rev. B 2012, 86 (12), 121204.

(5) Haberl, B.; Strobel, T. A.; Bradby, J. E. Pathways to Exotic Metastable Silicon Allotropes. Appl. Phys. Rev. 2016, 3 (4), 040808.

(6) Tonkov, E. Y.; Ponyatovsky, E. G. Phase Transformations of Elements under High Pressure; CRC press, 2004; Vol. 4.

(7) Ganguly, S.; Kazem, N.; Carter, D.; Kauzlarich, S. M. Colloidal Synthesis of an Exotic Phase of Silicon: The BC8 Structure. J. Am. Chem. Soc. 2014, 136 (4), 1296-1299.

(8) Haberl, B.; Guthrie, M.; Sinogeikin, S. V.; Shen, G.; Williams, J. S.; Bradby, J. E. Thermal Evolution of the Metastable R8 and BC8 Polymorphs of Silicon. High Press. Res. 2015, 35, 99-116.

(9) Zhang, H.; Liu, H.; Wei, K.; Kurakevych, O. O.; Le Godec, Y.; Liu, Z.; Martin, J.; Guerette, M.; Nolas, G. S.; Strobel, T. A. BC8 Silicon (Si-III) Is a Narrow-Gap Semiconductor. Phys. Rev. Lett. 2017, 118 (14), 146601.

(10) Hauge, H. I. T.; Verheijen, M. A.; Conesa-Boj, S.; Etzelstorfer, T.; Watzinger, M.; Kriegner, D.; Zardo, I.; Fasolato, C.; Capitani, F.; Postorino, P.; et al. Hexagonal Silicon Realized. Nano Lett. 2015, 15 (9), 5855-5860.

(11) Ammar, A.; Cros, C.; Pouchard, M.; Jaussaud, N.; Bassat, J.-M.; Villeneuve, G.; Duttine, M.; Ménétrier, M.; Reny, E. On the Clathrate Form of Elemental Silicon, Si 136: Preparation and Characterisation of $\mathrm{Na}_{\mathrm{x}} \mathrm{Si}_{136}(\mathrm{X} \rightarrow 0)$. Solid State Sci. 2004, 6, 393-400.

(12) Krishna, L.; Baranowski, L. L.; Martinez, A. D.; Koh, C. A.; Taylor, P. C.; Tamboli, A. C.; Toberer, E. S. Efficient Route to Phase Selective Synthesis of Type II Silicon Clathrates with Low Sodium Occupancy. CrystEngComm 2014, 16 (19), 3940-3949.

(13) Wentorf, R. H.; Kasper, J. S. Two New Forms of Silicon. Science 1963, 139 (3552), 338339.

(14) Gryko, J.; McMillan, P. F.; Marzke, R. F.; Ramachandran, G. K.; Patton, D.; Deb, S. K.; Sankey, O. F. Low-Density Framework Form of Crystalline Silicon with a Wide Optical Band Gap. Phys. Rev. B 2000, 62 (12), R7707.

(15) Blase, X. Quasiparticle Band Structure and Screening in Silicon and Carbon Clathrates. Phys. Rev. B 2003, 67 (3), 035211.

(16) Adams, G. B.; O’Keeffe, M.; Demkov, A. A.; Sankey, O. F.; Huang, Y.-M. Wide-BandGap Si in Open Fourfold-Coordinated Clathrate Structures. Phys. Rev. B 1994, 49 (12), 8048.

(17) Dong, J.; Sankey, O. F.; Kern, G. Theoretical Study of the Vibrational Modes and Their Pressure Dependence in the Pure Clathrate-II Silicon Framework. Phys. Rev. B 1999, 60 (2), 950 .

(18) Connétable, D. Structural and Electronic Properties of P-Doped Silicon Clathrates. Phys. Rev. B 2007, 75 (12), 125202.

(19) Martinez, A. D.; Krishna, L.; Baranowski, L. L.; Lusk, M. T.; Toberer, E. S.; Tamboli, A. C. Synthesis of Group IV Clathrates for Photovoltaics. IEEE J. Photovolt. 2013, 3 (4), 13051310 .

(20) Malone, B. D.; Cohen, M. L. Prediction of a Metastable Phase of Silicon in the Ibam Structure. Phys. Rev. B 2012, 85 (2), 024116. 
(21) Xiang, H. J.; Huang, B.; Kan, E.; Wei, S.-H.; Gong, X. G. Towards Direct-Gap Silicon Phases by the Inverse Band Structure Design Approach. Phys. Rev. Lett. 2013, 110 (11), 118702.

(22) Zwijnenburg, M. A.; Jelfs, K. E.; Bromley, S. T. An Extensive Theoretical Survey of LowDensity Allotropy in Silicon. Phys. Chem. Chem. Phys. 2010, 12 (30), 8505-8512.

(23) Kim, D. Y.; Stefanoski, S.; Kurakevych, O. O.; Strobel, T. A. Synthesis of an OpenFramework Allotrope of Silicon. Nat. Mater. 2015, 14 (2), 169-173.

(24) Kurakevych, O. O.; Strobel, T. A.; Kim, D. Y.; Muramatsu, T.; Struzhkin, V. V. Na-Si Clathrates Are High-Pressure Phases: A Melt-Based Route to Control Stoichiometry and Properties. Cryst. Growth Des. 2013, 13 (1), 303-307.

(25) Bryan, J. D.; Stucky, G. D. Eu4Ga8Ge $\mathrm{Gu}_{16}$ : A New Four-Coordinate Clathrate Network. Chem. Mater. 2001, 13 (2), 253-257.

(26) Wosylus, A.; Prots, Y.; Burkhardt, U.; Schnelle, W.; Schwarz, U. High-Pressure Synthesis of the Electron-Excess Compound CaSi6. Sci. Technol. Adv. Mater. 2007, 8 (5), 383-388.

(27) Wosylus, A.; Prots, Y.; Burkhardt, U.; Schnelle, W.; Schwarz, U.; Grin, Y. High-Pressure Synthesis of Strontium Hexasilicide. Z. Für Naturforschung B 2014, 61 (12), 1485-1492.

(28) Wosylus, A.; Demchyna, R.; Prots, Y.; Schnelle, W.; Schwarz, U. Refinement of the Crystal Structure of Barium Hexasilicide, BaSi6. Z. Für Krist. - New Cryst. Struct. 2014, 224 (3), 347-348.

(29) Wosylus, A.; Prots, Y.; Burkhardt, U.; Schnelle, W.; Schwarz, U.; Grin, Y. Breaking the Zintl Rule: High-Pressure Synthesis of Binary EuSi 6 and Its Ternary Derivative EuSi ${ }_{6-\mathrm{x}} \mathrm{Ga}_{\mathrm{x}}$ $(0 \leqslant x \leqslant 0.6)$. Solid State Sci. 2006, $8(7), 773-781$.

(30) Baerlocher, C.; McCusker, L. B.; Olson, D. H. Atlas of Zeolite Framework Types; Elsevier, 2007.

(31) Ouyang, T.; Zhang, P.; Xiao, H.; Tang, C.; Li, J.; He, C.; Zhong, J. Potential Thermoelectric Material Open Framework $\mathrm{Si}_{24}$ from a First-Principles Study. J. Phys. Appl. Phys. 2017.

(32) Chae, K.; Kang, S.-H.; Choi, S.-M.; Kim, D. Y.; Son, Y.-W. Enhanced Thermoelectric Properties in a New Silicon Crystal Si24 with Intrinsic Nanoscale Porous Structure. Nano Lett. 2018.

(33) Arrieta, U.; Katcho, N. A.; Arcelus, O.; Carrasco, J. First-Principles Study of Sodium Intercalation in Crystalline $\mathrm{Na}_{\mathrm{x}} \mathrm{Si}_{24}(0 \leq \mathrm{x} \leq 4)$ as Anode Material for Na-Ion Batteries. Sci. Rep. 2017, 7.

(34) Hybertsen, M. S.; Louie, S. G. First-Principles Theory of Quasiparticles: Calculation of Band Gaps in Semiconductors and Insulators. Phys. Rev. Lett. 1985, 55 (13), 1418-1421.

(35) Green, M. A. Self-Consistent Optical Parameters of Intrinsic Silicon at $300 \mathrm{~K}$ Including Temperature Coefficients. Sol. Energy Mater. Sol. Cells 2008, 92 (11), 1305-1310.

(36) Linghu, J.; Shen, L.; Yang, M.; Xu, S.; Feng, Y. P. Si24: An Efficient Solar Cell Material. J. Phys. Chem. C 2017.

(37) Lewis, N. S.; Crabtree, G. Basic Research Needs for Solar Energy Utilization: Report of the Basic Energy Sciences Workshop on Solar Energy Utilization, April 18-21, 2005; Lewis, N. S., Crabtree, G., Nozik, A. J., Wasielewski, M. R., Alivisatos, P., Eds.; US Department of Energy, Office of Basic Energy Science: Washington, DC, 2005.

(38) Shockley, W.; Queisser, H. J. Detailed Balance Limit of Efficiency of P-N Junction Solar Cells. J. Appl. Phys. 1961, 32 (3), 510-519.

(39) Guerette, M.; Strobel, T. A.; Zhang, H.; Juhl, S.; Alem, N.; Lokshin, K.; Krishna, L.; Taylor, P. C. Advanced Synthesis of $\mathrm{Na}_{4} \mathrm{Si}_{24}$. MRS Adv. 2018, 3 (25), 1427-1433. 
(40) Walker, D. Lubrication, Gasketing, and Precision in Multianvil Experiments. Am. Mineral. 1991, 76 (7-8), 1092-1100.

(41) Walker, D.; Carpenter, M.; Hitch, C. Some Simplifications to Multianvil Devices for HighPressure Experiments. Am. Mineral. 1990, 75 (9-10), 1020-1028.

(42) Bertka, C. M.; Fei, Y. Mineralogy of the Martian Interior up to Core-Mantle Boundary Pressures. J. Geophys. Res. Solid Earth 1997, 102 (B3), 5251-5264.

(43) Multianvil Web Page http://multianvil.asu.edu/MainPage_Cell.html (accessed Apr 18, 2018).

(44) AZtecEnergy - EDS software - Oxford Instruments https://www.oxfordinstruments.com/products/microanalysis/energy-dispersive-X-ray-systems-eds-edx/edsfor-sem/eds-software-aztec (accessed Apr 18, 2018).

(45) JADE for XRD https://materialsdata.com/prodjd.html (accessed Apr 18, 2018).

(46) Bruker. APEX3; Bruker AXS Inc., Madison, Wisconsin, USA, 2012.

(47) Sheldrick, G. M. SADABS; University of Gottingen, Germany, 1996.

(48) Sheldrick, G. A Short History of SHELX. Acta Crystallogr. Sect. A 2008, 64 (1), 112-122.

(49) Sheldrick, G. Crystal Structure Refinement with SHELXL. Acta Crystallogr. Sect. C 2015, $71(1), 3-8$.

(50) Gelato, L. M.; Parthe, E. STRUCTURE TIDY - a Computer Program to Standardize Crystal Structure Data. J. Appl. Crystallogr. 1987, 20 (2), 139-143.

(51) Parthe, E.; Gelato, L. M. The Standardization of Inorganic Crystal-Structure Data. Acta Crystallogr. Sect. A 1984, 40 (3), 169-183.

(52) Palmer, D. CrystalMaker; CrystalMaker Software Ltd.: Oxford, England, 2015.

(53) Jouini, Z.; Kurakevych, O. O.; Moutaabbid, H.; Godec, Y. L.; Mezouar, M.; Guignot, N. Phase Boundary between Na-Si Clathrates of Structures I and II at High Pressures and High Temperatures. J. Superhard Mater. 2016, 38 (1), 66-70.

(54) Yamanaka, S.; Komatsu, M.; Tanaka, M.; Sawa, H.; Inumaru, K. High-Pressure Synthesis and Structural Characterization of the Type II Clathrate Compound $\mathrm{Na}_{30.5} \mathrm{Si}_{136}$ Encapsulating Two Sodium Atoms in the Same Silicon Polyhedral Cages. J. Am. Chem. Soc. 2014, 136 (21), 7717-7725.

(55) Kubo, A.; Wang, Y.; Runge, C. E.; Uchida, T.; Kiefer, B.; Nishiyama, N.; Duffy, T. S. Melting Curve of Silicon to $15 \mathrm{GPa}$ Determined by Two-Dimensional Angle-Dispersive Diffraction Using a Kawai-Type Apparatus with X-Ray Transparent Sintered Diamond Anvils. J. Phys. Chem. Solids 2008, 69, 2255-2260.

(56) Yang, C. C.; Li, J. C.; Jiang, Q. Effect of Pressure on Melting Temperature of Silicon Determined by Clapeyron Equation. Chem. Phys. Lett. 2003, 372 (1-2), 156-159.

(57) Kaczmarski, M.; Bedoya-Martínez, O. N.; Hernández, E. R. Phase Diagram of Silicon from Atomistic Simulations. Phys. Rev. Lett. 2005, 94 (9), 095701.

(58) Łopaciński, M.; Puszynski, J.; Lis, J. Synthesis of Ternary Titanium Aluminum Carbides Using Self-Propagating High-Temperature Synthesis Technique. J. Am. Ceram. Soc. 2001, 84 (12), 3051-3053.

(59) Lin, H.; Zhou, S.; Teng, H. Synthesis of $\mathrm{Tb}_{3} \mathrm{Al}_{5} \mathrm{O}_{12}$ (TAG) Transparent Ceramics for Potential Magneto-Optical Applications. Opt. Mater. 2011, 33 (11), 1833-1836.

(60) Gesing, T. M.; Fischer, R. X.; Burianek, M.; Mühlberg, M.; Debnath, T.; Rüscher, C. H.; Ottinger, J.; Buhl, J.-C.; Schneider, H. Synthesis and Properties of Mullite-Type $\left(\mathrm{Bi}_{1-\mathrm{x}} \mathrm{Sr}_{\mathrm{x}}\right)_{2}$ $\left(\mathrm{M}_{1-\mathrm{y}}^{1} \mathrm{M}_{\mathrm{y}}^{2}\right)_{4} \mathrm{O}_{9-\mathrm{x}}(\mathrm{M}=\mathrm{Al}, \mathrm{Ga}, \mathrm{Fe})$. J. Eur. Ceram. Soc. 2011, 31 (16), 3055-3062. 
(61) Ma, C.-B. Reinvestigation of the Olivine-Spinel Transformation in $\mathrm{Ni}_{2} \mathrm{SiO}_{4}$ and the Incongruent Melting of $\mathrm{Ni}_{2} \mathrm{SiO}_{4}$ Olivine. J. Geophys. Res. 1974, 79 (23), 3321-3324.

(62) Williams, D. B.; Carter, C. B.; Veyssiere, P. Transmission Electron Microscopy: A Textbook for Materials Science; Springer, 1998; Vol. 10.

(63) Yan, C.; Vohra, Y. K.; Mao, H.; Hemley, R. J. Very High Growth Rate Chemical Vapor Deposition of Single-Crystal Diamond. Proc. Natl. Acad. Sci. 2002, 99 (20), 12523-12525.

(64) Spitsyn, B. V.; Bouilov, L. L.; Derjaguin, B. V. Vapor Growth of Diamond on Diamond and Other Surfaces. J. Cryst. Growth 1981, 52, 219-226.

(65) Kamo, M.; Sato, Y.; Matsumoto, S.; Setaka, N. Diamond Synthesis from Gas Phase in Microwave Plasma. J. Cryst. Growth 1983, 62 (3), 642-644.

(66) Chen, W.; Hamon, G.; Léal, R.; Maurice, J.-L.; Largeau, L.; Roca i Cabarrocas, P. Growth of Tetragonal Si via Plasma-Enhanced Epitaxy. Cryst. Growth Des. 2017, 17 (8), 42654269.

\section{For Table of Contents Use Only}

SYNOPSIS

Pressure, temperature, and initial materials have been optimized for growth of $\mathrm{Na}_{4} \mathrm{Si}_{24}$, yielding large single crystals. This is the precursor to $\mathrm{Si}_{24}$, a metastable form of silicon with a quasi-direct band gap at $1.3 \mathrm{eV}$ with potential to revolutionize optoelectronics. We show possible epitaxy with traditional silicon, and high $\mathrm{Na}$ mobility foretells easy $\mathrm{Na}$ removal for bulk conversion to $\mathrm{Si}_{24}$.

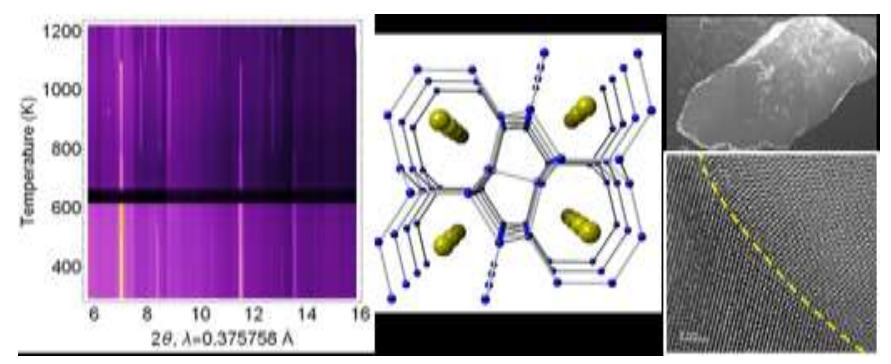

